\title{
Effects of ingested fructose and infused glucagon on endogenous glucose production in obese NIDDM patients, obese non-diabetic subjects, and healthy subjects
}

\author{
N. Paquot ${ }^{1}$, Ph. Schneiter ${ }^{2}$, E. Jéquier ${ }^{2}$, R. Gaillard ${ }^{3}$, P.J. Lefèbvre ${ }^{1}$, A. Scheen ${ }^{1}$, L. Tappy ${ }^{2,4}$ \\ ${ }^{1}$ Service de Diabétologie, Nutrition et Maladies Métaboliques, Département de Médecine, CHU Sart Tilman, Liège, Belgium \\ ${ }^{2}$ Institut de Physiologie, Faculté de Médecine, Université de Lausanne, Switzerland \\ ${ }^{3}$ Division d'Endocrinologie et du Métabolisme, CHUV, Lausanne, Switzerland \\ ${ }^{4}$ Policlinique Médicale Universitaire, Lausanne, Switzerland
}

\begin{abstract}
Summary
Increased endogenous glucose production (EGP) and gluconeogenesis contribute to the patho-genesis of hyperglycaemia in non-insulin-dependent diabetes mellitus (NIDDM). In healthy subjects, however, EGP remains constant during administration of gluconeogenic precursors. This study was performed in order to determine whether administration of fructose increases EGP in obese NIDDM patients and obese non-diabetic subjects. Eight young healthy lean subjects, eight middle-aged obese NIDDM patients and seven middle-aged obese non-diabetic subjects were studied during hourly ingestion of ${ }^{13} \mathrm{C}$ fructose $\left(0.3 \mathrm{~g} \cdot \mathrm{kg}\right.$ fat free $\left.\mathrm{mass}^{-1} \cdot \mathrm{h}^{-1}\right)$ for $3 \mathrm{~h}$. Fructose failed to increase EGP (measured with $6,6^{2} \mathrm{H}$ glucose) in NIDDM $(17.7 \pm 1.9 \mu \mathrm{mol} \cdot \mathrm{kg}$ fat free mass $^{-1} \cdot \min ^{-1}$ basal vs $15.9 \pm 0.9$ after fructose $)$, in obese non-diabetic subjects $(12.1 \pm 0.5$ basal vs $13.1 \pm 0.5$ after fructose) and in lean healthy subjects (13.3 \pm 0.5 basal vs $13.8 \pm 0.6$ after fructose) although ${ }^{13} \mathrm{C}$ glucose synthesis contributed $73.2 \%$ of EGP in lean subjects, $62.6 \%$ in obese non-diabetic subjects, and $52.8 \%$ in obese NIDDM patients. Since glucagon may play an important role in the development of hyperglycaemia in NIDDM, healthy subjects were also studied during ${ }^{13} \mathrm{C}$ fructose ingestion + hyperglucagonaemia $(232 \pm 9 \mathrm{ng} / \mathrm{l})$ and during hyperglucagonaemia alone. EGP increased by $19.8 \%$ with ingestion of fructose + glucagon $(p<$ 0.05 ) but remained unchanged during administration of fructose or glucagon alone. The plasma ${ }^{13} \mathrm{C}$ glucose enrichment was identical after fructose ingestion both with and without glucagon, indicating that the contribution of fructose gluconeogenesis to the glucose 6-phosphate pool was identical in these two conditions. We concluded that during fructose administration: 1) gluconeogenesis is increased, but EGP remains constant in NIDDM, obese non-diabetic, and lean individuals; 2) in lean individuals, both an increased glucagonaemia and an enhanced supply of gluconeogenic precursors are required to increase EGP; this increase in EGP occurs without changes in the relative proportion of glucose 6-phosphate production from fructose and from other sources (i. e. glycogenolysis + gluconeogenesis from non-fructose precursors). [Diabetologia (1996) 39: 580$586]$
\end{abstract}

Keywords: glycogenolysis ; carbohydrate oxidation ; glucagons ; gluconeogenesis ; fructose.

Abbreviations: EGP, Endogenous glucose production ; CHO, carbohydrate ; APE, atom percent excess ; GRd, glucose rate of disappearance ; FFM, fat-free mass.

In healthy human subjects and in normal dogs, endogenous glucose production (EGP) has been shown not to rise when gluconeogenic substrates are infused and gluconeogenesis is increased [1-5]. This constancy of EGP was also observed during infusions of lactate [2] or fructose [5] when insulin and glucagon were maintained constant by infusions of somatostatin, insulin and glucagon, indicating autoregulation. The mechanisms responsible for this autoregulation of EGP may involve inhibition of gluconeogenesis from endogenous substrates [3] and/or of glucogenolysis [2] and stimulation of glycogen synthesis [5]. In non-insulin-dependent diabetic (NIDDM) patients, EGP is increased and correlates with fasting plasma glucose [6]. Hepatic balance of gluconeogenic precursors [7], estimation of hepatic glycogen degradation by in vivo nuclear magnetic resonance spectroscopy [8] and assessment of Cori cycle activity [9], all indicate that an increased gluconeogenesis accounts for a substantial part of this increase in EGP. It may be hypothesized that a rise in gluconeogenic substrate availability $[10,11]$ secondary to peripheral insulin resistance is responsible for both stimulation of gluconeogenesis and EGP. In the first part of this study, we measured the alterations induced by fructose ingestion on whole body and hepatic glucose metabolism in young lean healthy control subjects, in middle-aged obese non-diabetic subjects, and in middle-aged obese NIDDM patients.

The second part of this study aimed to assess whether the alterations of the regulation of glucagon secretion which are frequently encountered in NIDDM might alter the regulation of EGP during fructose administration. It has been shown that glucagon secretion is increased, or inappropriately decreased in NIDDM patients following 
meals. Moreover, this relative hyperglucagonaemia has been shown to participate in the development of hyperglycaemia [12]. We have also shown that amino acids increase EGP when infused together with exogenous glucose [13] or during hyperinsulinaemic clamps and that amino acid-induced glucagon secretion plays a pivotal role in stimulating EGP in this condition [14]. We therefore assessed the effect of hyperglucagonaemia on fructose-induced gluconeogenesis and on EPG in lean healthy subjects.

\section{Subjects and methods}

Subjects. Eight young healthy human volunteers [four males, four females, age 23.1 \pm 0.8 years (mean $\pm \mathrm{SEM}$ ), weight $71.7 \pm 3.7 \mathrm{~kg}$, height $174.1 \pm 1.9 \mathrm{~cm}$, fat free mass $(\mathrm{FFM})$ (determined from skinfold thickness measurements [15]) $56.0 \pm 3.7 \mathrm{~kg}$ ] were selected to participate in three protocols. All were in good physical health, were not currently taking any medication, and had no family history of diabetes or related disorders. Eight middle-aged obese NIDDM patients (four males, four females, mean age $55.5 \pm 3.0$ years, weight $88.2 \pm$ $6.8 \mathrm{~kg}$, height $167.4 \pm 2.4 \mathrm{~cm}$, FFM $52.6 \pm 2.5 \mathrm{~kg}$ ) and 7 middle-aged obese subjects with normal glucose tolerance (assessed with a standard 75-g oral glucose tolerance test) (seven females, mean age $41.1 \pm 4.1$ years, weight $92.8 \pm 4.6 \mathrm{~kg}$, height $164.5 \pm 2.5 \mathrm{~cm}$, FFM $54.5 \pm 3.9 \mathrm{~kg}$ were recruited to participate in protocol 1. NIDDM subjects were maintained in good metabolic control with oral anti-diabetic agents (mean $\mathrm{HbA}_{1 \mathrm{c}} 5.9 \pm$ $0.9 \%$ ) and were not taking any other medication. They discontinued all drug treatment 4 days prior to the study. All subjects had maintained a steady body weight for at least 3 months before taking part in the study. They were placed on an isocaloric, $50 \%$ carbohydrate diet devoid of foods naturally enriched in ${ }^{13} \mathrm{C}$ during the 3 days preceding each study.

Experimental protocols were approved by the ethical committees of Lausanne and Liège Schools of Medicine.

General procedures. All experiments began between 07.00 and 09.00 hours after a 10-12-h fast. After having voided urine, the subjects lay in the supine position and an indwelling venous cannula was inserted into an antecubital vein of one arm. A primed $(3000 \mu \mathrm{g} / \mathrm{kg})$ continuous $\left(30 \mu \mathrm{g} \cdot \mathrm{kg}^{-1} \cdot \mathrm{min}^{-1}\right)$ infusion of $6,6^{2} \mathrm{H}$ glucose ( $1 \mathrm{~g} / \mathrm{l}$; Isotech Inc., Miamisburg, Ohio, USA) was started at time -180 min and was continued throughout the 6-h experiment. A second cannula was inserted into a wrist vein of the contralateral arm and was used to collect blood samples periodically between time -30 and $180 \mathrm{~min}$. This hand was placed in a thermostabilized box heated to $60^{\circ} \mathrm{C}$ in order to achieve partial arterialization of venous blood (oxygen saturation 70-80\%). Respiratory gas exchanges were monitored between -60 and $180 \mathrm{~min}$ by continuous flow indirect calorimetry, using a ventilated canopy [16]. The air at the inlet and outlet of the canopy was continuously analysed for $\mathrm{O}_{2}$ (Magnos 3G delta; Hartmann and Braun, Frankfurt, Germany) and $\mathrm{CO}_{2}$ (Uras 3G delta; Hartmann and Braun), and the total air flow through the canopy was measured with a digital pneumotachograph (Godart-stathan BV, Bilthoven, The Netherlands). Breath samples were collected at intervals for determination of ${ }^{13} \mathrm{CO}_{2}$.

Protocol 1: Eight young healthy subjects, seven middle-aged obese non-diabetic subjects, and eight middle-aged obese NIDDM patients took part in this protocol. After a 2-h equilibration period, baseline data were collected between -60 and $0 \mathrm{~min}$. Subsequently a fructose load $(300 \mathrm{mg} / \mathrm{kg}$ FFM, dissolved in $50 \mathrm{ml}$ lemon-flavoured water) enriched with $1-{ }^{13} \mathrm{C}$ fructose (Isotech Inc.) at $1.113 \%{ }^{13} \mathrm{C}$ was administered orally once every hour until time $180 \mathrm{~min}$. It was assumed that the total amount of fructose absorbed during the period 120-180 min was 300 $\mathrm{mg} / \mathrm{kg} \mathrm{FFM}$, or $5 \mathrm{mg} \cdot \mathrm{kg} \mathrm{FFM}{ }^{-1} \cdot \mathrm{min}^{-1}$.

The eight healthy subjects studied in protocol 1 also participated in protocols 2 and 3 .

Protocol 2: This protocol was identical to protocol 1 but, in addition, glucagon (Glucagène; Novo Nordisk, Copenhagen, Denmark) was infused at a rate of $3 \mathrm{ng} \cdot \mathrm{kg}^{-1} \cdot \mathrm{min}^{-1}$ between 0 and $180 \mathrm{~min}$.

Protocol 3: This protocol was designed to evaluate the effects of hyperglucagonaemia alone on glucose production and oxidation. For this purpose, subjects were infused with glucagon at a rate of $3 \mathrm{ng} \cdot \mathrm{kg}^{-1} \cdot \mathrm{min}^{-1}$ between 0 and $180 \mathrm{~min}$, but did not receive any fructose.

Glucose kinetics: Glucose rates of appearance (which were equal to EGP) and of disappearance $\left(\mathrm{GR}_{\mathrm{d}}\right)$ were calculated from plasma $6,6{ }^{2} \mathrm{H}$ enrichment during the periods $-30-0 \mathrm{~min}$ and 120-180 min. Steele's equations for steady-state conditions were used for this purpose [17]. The contribution of gluconeogenesis from fructose to EGP (EGP(F)) was calculated during the period 300-360 min from the rate of ${ }^{13} \mathrm{C}$ glucose appearance using the equation of Chiasson et al. [18]. Glucose production from sources other than fructose $\left(\mathrm{EGP}_{(\text {non-F) }}\right)$ (i.e. from glycogenolysis and gluconeogenesis from lactate, amino acids and glycerol) was calculated as:

$$
\mathrm{EGP}_{(\mathrm{non}-\mathrm{F})}=\mathrm{EGP}-\mathrm{EGP}(\mathrm{F})
$$

Substrate oxidation rates. Net carbohydrate oxidation rates were calculated from respiratory gas exchanges and urinary nitrogen excretion corrected for changes in blood urea nitrogen [19] using the equations of Livesey and Elia [20]. ${ }^{13} \mathrm{C}$ fructose oxidation was calculated as: 


$$
\begin{aligned}
& { }^{13} \mathrm{C} \mathrm{F} \text { ox }\left(\mu \mathrm{mol} \cdot \mathrm{kg} \mathrm{FFM}^{-1} \cdot \min ^{-1}\right)=\frac{\text { breath }{ }^{13} \mathrm{CO}_{2}}{\text { infused }{ }^{13} \mathrm{C} \text { fructose }} \\
& \dot{\mathrm{VCO}_{2}} \cdot \frac{1}{0.8} \cdot \frac{1}{0.134} \cdot \frac{1}{\mathrm{FFM}}
\end{aligned}
$$

where breath ${ }^{13} \mathrm{CO}_{2}$ and infused ${ }^{13} \mathrm{C}$ fructose are expressed in atom $\%$ excess (APE) and $\& \mathrm{CO}_{2}$ in $\mathrm{ml} / \mathrm{min}$; FFM is fat-free mass in $\mathrm{kg}$ and 0.8 is a correction for incomplete recovery of ${ }^{13} \mathrm{CO}_{2}$ in breath [21]; 0.134 is the $\mathrm{ml}$ of $\mathrm{CO}_{2}$ produced during oxidation of $1 \mu \mathrm{mol}$ fructose. Non-oxidative fructose disposal was calculated as: Non-ox $\mathrm{FD}=$ fructose ingested $-{ }^{13} \mathrm{C}$ fructose ox Non-ox FD represents mainly glucose synthesis from fructose with glycogen deposition of the neoformed glucose and de novo lipogenesis from fructose. However, the latter process appears to be quantitatively small.

Analytical procedures. Plasma $6,6{ }^{2} \mathrm{H}$ glucose was measured by GC-MS (HP) of penta-acetylated glucose in electron impact mode, with selected monitoring of $\mathrm{m} / \mathrm{z} 242.1$ and 244.1 . Plasma ${ }^{13} \mathrm{C}$ glucose was purified by HPLC [22] and analysed by isotope ratio mass spectrometry (Roboprep CN/Tracermass; Europa Scientific, Crewe, U.K.). Breath ${ }^{13} \mathrm{CO}_{2}$ was measured by isotope ratio mass spectrometry (Roboprep g/Tracermass; Europa Scientific). Plasma insulin (kit from Biodata SpA, Guidonia Montecelio, Italy) and glucagon (kit KGND ${ }_{1}$; DPC, Los Angeles, Calif., USA) were measured by radioimmunoassay. Plasma and urine fructose [23] were measured enzymatically. Plasma non-esterified fatty acids were measured colorimetrically using a kit from Wako (Freiburg, Germany). Urinary nitrogen was measured with the method of Kjehldahl [24].

\section{Statistical analysis}

All data are expressed as mean \pm SEM unless stated otherwise. Data were averaged to a single value for periods 60-0 min (except for glucose kinetics for which the period -30-0 min was considered) and 120-180 min. Comparisons between healthy volunteers, obese non-diabetic subjects and obese NIDDM patients were performed during each of these two periods with modified analysis of variance and unpaired f-tests. Comparison between healthy subjects during protocols 1, 2 and 3 were performed with modified analysis of variance and paired f-tests.

\section{Results}

Basal substrate and hormone concentrations are shown in Table 1. NIDDM patients had a $55 \%$ increase in plasma glucose concentration $(p<0.01)$ and $47 \%$ increase in plasma non-esterified fatty acid concentrations (NS), and obese non-diabetic subjects had an $80 \%$ increase in plasma non-esterified fatty acid concentrations (NS) vs lean healthy subjects. Net carbohydrate $(\mathrm{CHO})$ oxidation in the basal state averaged $11.4 \pm 1.1 \mu \mathrm{mol} \cdot \mathrm{kg}$ $\mathrm{FFM}^{-1} \cdot \mathrm{min}^{-1}$ in healthy subjects, $7.8 \pm 1.5 \mu \mathrm{mol} \cdot \mathrm{kg} \mathrm{FFM}^{-1} \cdot \mathrm{min}^{-1}$ in obese non-diabetic subjects (NS) and $8.2 \cdot$ $0.6 \mu \mathrm{mol} \cdot \mathrm{kg} \mathrm{FFM}^{-1} \cdot \mathrm{min}^{-1}$ in NIDDM patients $(p<0.05 \mathrm{vs}$ lean healthy subjects). Basal EGP was increased by $33.1 \%$ in NIDDM patients ( $p<0.05$ vs lean subjects) but not in obese non-diabetic patients compared to lean control subjects (Table 2).

Table 1. Plasma glucose, fructose, insulin, glucagon and non-esterified fatty acid concentrations before and

\begin{tabular}{|c|c|c|c|c|c|c|c|c|c|c|c|}
\hline & \multirow[t]{2}{*}{$n$} & \multicolumn{2}{|c|}{ Glucose $(\mathrm{mmol} / \mathrm{l})$} & \multicolumn{2}{|c|}{ Insulin (pmol/l) } & \multicolumn{2}{|c|}{$\begin{array}{l}\text { Non-esterified fatty } \\
\text { acids }(\mathrm{mmol} / \mathrm{l})\end{array}$} & \multicolumn{2}{|c|}{ Glucagon (ng/l) } & \multicolumn{2}{|c|}{ Fructose $(\mathrm{mmol} / \mathrm{l})$} \\
\hline & & $\overline{\text { Basal }}$ & Fructose & Basal & Fructose & Basal & Fructose & Basal & Fructose & Basal & Fructose \\
\hline $\begin{array}{l}\text { Lean } \\
\text { subjects } \\
\text { Obese }\end{array}$ & 8 & $4.82 \pm 0.12$ & $5.16 \pm 0.14^{\mathrm{a}}$ & $29.9 \pm 4.1$ & $47.6 \pm 6.1^{\mathrm{b}}$ & $0.59 \pm 0.11$ & $0.43 \pm 0.13^{b}$ & $105 \pm 6$ & $103 \pm 4$ & $0 \pm 0$ & $0.18 \pm 0.03^{\mathrm{c}}$ \\
\hline $\begin{array}{l}\text { subjects } \\
\text { Obese } \\
\text { NIDDM } \\
\text { patients }\end{array}$ & 7 & $5.02 \pm 0.10$ & $5.26 \pm 0.13^{\mathrm{a}}$ & $56.0 \pm 12.9$ & $73.0 \pm 13.7$ & $1.06 \pm 0.24$ & $0.61 \pm 0.13^{\mathrm{b}}$ & $78 \pm 11$ & $61 \pm 3$ & $0 \pm 0$ & $0.35 \pm 0.05^{\text {cd }}$ \\
\hline
\end{tabular}
during fructose administration 
Table 2. Endogenous glucose production (EGP) in the subjects studied

\begin{tabular}{|c|c|c|c|c|c|}
\hline & \multirow[t]{2}{*}{$n$} & \multirow{2}{*}{$\begin{array}{l}\text { Basal state } \\
\mathrm{EGP} \\
\left(\mu \mathrm{mol} \cdot \mathrm{kg} \mathrm{FFM}^{-1} \cdot \mathrm{min}^{-1}\right)\end{array}$} & \multicolumn{3}{|c|}{ Fructose administration } \\
\hline & & & EGP & $\begin{array}{l}\text { EGP (F) } \\
\left(\mu \mathrm{mol} \cdot \mathrm{kg} \mathrm{FFM}^{-1} \cdot \mathrm{min}^{-1}\right)\end{array}$ & EGP (NF) \\
\hline Lean subjects & 8 & $13.3 \pm 0.5$ & $13.8 \pm 0.6$ & $10.1 \pm 1.2$ & $3.7 \pm 0.9$ \\
\hline Obese subjects & 7 & $12.1 \pm 0.5$ & $13.1 \pm 0.5$ & $8.2 \pm 0.7$ & $4.9 \pm 0.8$ \\
\hline Obese NIDDM patients & 8 & $17.7 \pm 1.7^{\mathrm{a}}$ & $15.9 \pm 0.9$ & $8.4 \pm 1.2$ & $7.5 \pm 0.8^{b}$ \\
\hline
\end{tabular}

EGP (F), Gluconeogenesis from fructose; EGP (NF), endogenous glucose production from sources other than fructose ${ }^{\mathrm{a}} p<0.05$ and ${ }^{\mathrm{b}} p<$ 0.01 vs lean subjects

Effects of fructose ingestion on glucose metabolism in young healthy lean subjects, middle-aged obese nondiabetic subjects, and middle-aged obese NIDDM patients (protocol 1). The effects of fructose ingestion on plasma glucose, fructose, ${ }^{13} \mathrm{C}$ glucose APE and breath ${ }^{13} \mathrm{CO}_{2}$ APE are shown in Figure 1. Fructose ingestion slightly increased plasma glucose and markedly decreased plasma non-esterified fatty acid concentrations in all three groups of subjects (Fig. 1; Table 1). Plasma fructose concentrations were slightly higher in obese nondiabetic subjects than in lean subjects $(p<0.05)$. EGP(F) was slightly lower in obese non-diabetic and in obese NIDDM subjects, but the difference was not significant. EGP was not altered by fructose ingestion although ${ }^{13} \mathrm{C}$ glucose synthesis contributed $73.2 \%$ of EGP in lean subjects, $62.6 \%$ in obese non-diabetic subjects, and $52.8 \%$ in obese NIDDM patients (Table 2). The stimulation by fructose of net $\mathrm{CHO}$ oxidation and the inhibition of net lipid oxidation were similar in obese and lean subjects. In NIDDM patients, the stimulation of CHO oxidation and of fructose oxidation and the inhibition of net lipid oxidation were blunted, resulting in a marked increase in net non-oxidative $\mathrm{CHO}$ disposal and in a slight increase in non-oxidative fructose disposal (Table 3). This nonoxidative fructose disposal indicates an increased rate of net glycogen deposition and/or de novo lipogenesis.

Fig.1. Plasma glucose, fructose and ${ }^{13} \mathrm{C}$ glucose $\mathrm{APE}$ and breath ${ }^{13} \mathrm{CO}_{2}$ APE in young lean subjects (-口-), middle-aged obese non-diabetic subjects (-O-) and middle-aged obese patients with NIDDM (- - - -

Fructose was administered once every hour starting at time $0 \mathrm{~min}$
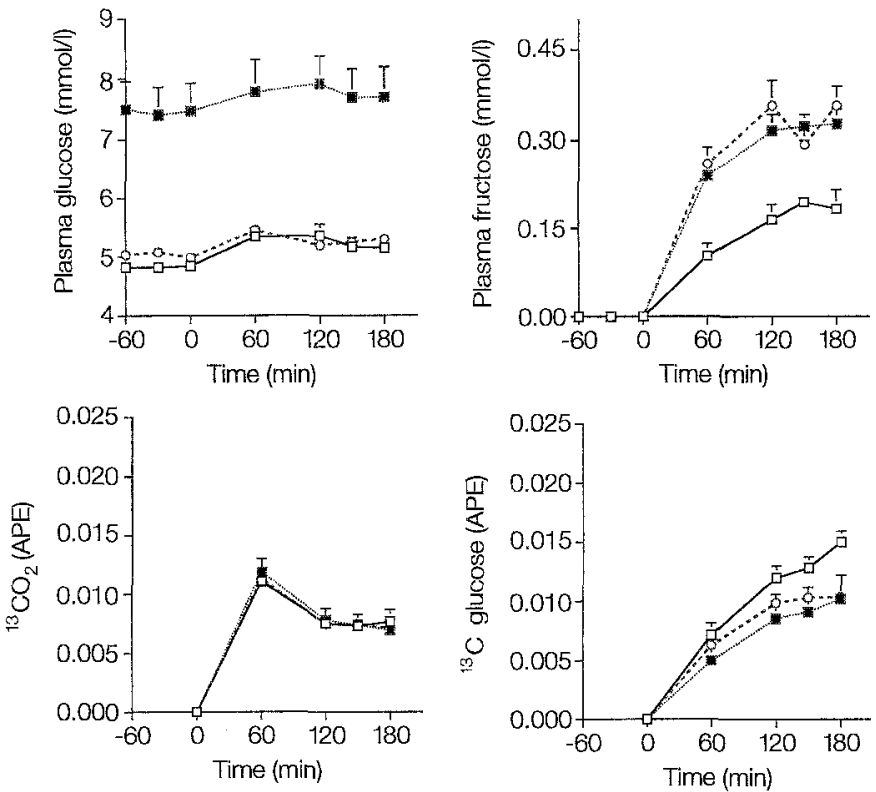

Table 3. Effects of fructose administration on net carbohydrate oxidation (CHO ox), fructose oxidation $\left({ }^{13} \mathrm{C} \mathrm{F}\right.$ ox) non-oxidative fructose disposal (non ox $F d$ ) and net lipid oxidation (Lox)

\begin{tabular}{llllll}
\hline & $n$ & $\begin{array}{l}\text { Increase in } \mathrm{CHO}^{\mathrm{b}}{ }^{\mathrm{b}} \\
\left(\mu \mathrm{mol} \cdot \mathrm{kg} \mathrm{FFM}^{-1} \cdot\right. \\
\left.\mathrm{min}^{-1}\right)\end{array}$ & $\begin{array}{l}{ }^{13} \mathrm{CFox}(\mu \mathrm{mol} \cdot \mathrm{kg} \\
\left.\mathrm{FFM}^{-1} \cdot \mathrm{min}^{-1}\right)\end{array}$ & $\begin{array}{l}\text { Non ox F d }(\mu \mathrm{mol} \cdot \\
\left.\mathrm{kg} \mathrm{FFM}^{-1} \cdot \mathrm{min}^{-1}\right)\end{array}$ & $\begin{array}{l}\text { Decrease in Lox } \\
\left.\mathrm{kg} \mathrm{FFM}^{-1} \cdot \mathrm{min}^{-1}\right)\end{array}$ \\
\hline Lean subjects & 8 & $7.5 \pm 0.8$ & $10.7 \pm 0.6$ & $17.0 \pm 0.6$ & $0.40 \pm 0.09$ \\
Obese subjects & 7 & $7.3 \pm 1.4$ & $9.7 \pm 0.6$ & $18.1 \pm 0.6$ & $0.41 \pm 0.15$ \\
Obese NIDDM patients & 8 & $4.7 \pm 1.0^{\mathrm{a}}$ & $8.7 \pm 0.2^{\mathrm{a}}$ & $19.0 \pm 0.2^{\mathrm{a}}$ & $0.26 \pm 0.14^{\mathrm{a}}$ \\
\hline
\end{tabular}


Effects of hyperglucagonaemia + fructose on glucose metabolism in healthy lean subjects (protocol 2). Infusion of glucagon increased plasma glucagon concentrations by $108.0 \%$ (Table 4). When fructose was ingested during hyperglucagonaemia, EGP increased by $19.8 \%$ (Fig. 2) $(p<0.001)$. However, plasma ${ }^{13} \mathrm{C}$ glucose enrichment (which is a reflection of the enrichment of the intrahepatic glucose 6-phosphate) was identical with or without glucagon (Fig. 3), indicating that both glucose synthesized from fructose and glucose originating from other sources (i. e. glycogenolysis and gluconeogenesis from other precursors) contributed equally to this increase in EGP. As a consequence of the increase in EGP, plasma glucose and insulin were increased by $29.2(p<0.01)$ and $133.3 \%(p<0.001)$, respectively (Table 4$).{ }^{13} \mathrm{C}$ fructose oxidation, non-oxidative fructose disposal, and the increment in net $\mathrm{CHO}$ ox (Fig. 4), and net non-oxidative CHO disposal (6.3 $\pm 1.8 \mathrm{vs} 7.3 \pm 2.5 \mu \mathrm{mol}^{\circ} \mathrm{kg}^{-1}$. $\mathrm{mm}^{-1}$ ) were identical without or with hyperglucagonaemia.

Effects of hyperglucagonaemia alone on glucose metabolism in healthy lean subjects (protocol 3). Infusion of glucagon increased plasma glucagon concentration in the same range as in protocol 2. However, EGP did not increase (Fig. 2) and net CHO oxidation tended to increase (Fig. 4) $(p=0.14)$ while lipid oxidation decreased slightly $(p=0.052)$. Slight rises in plasma glucose levels (from $4.8 \pm 0.1$ to $5.4 \pm 0.1 \mathrm{mmol} / 1, p<0.01$ ) and insulin levels (from $28.5 \pm 5.6$ to $35.3 \pm 3.6 \mathrm{pmol} / \mathrm{l}, p<0.01$ ) were also observed (Table 4 ).

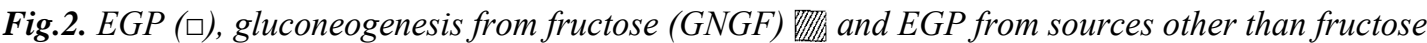
$(E G P(N F)$ 霊) in lean healthy subjects in the basal state and during fructose administration $(F)$, fructose administration and glucagon infusion $(F+G)$ and glucagon infusion alone $(G)$. ${ }^{*} p<0.001$ vs basal

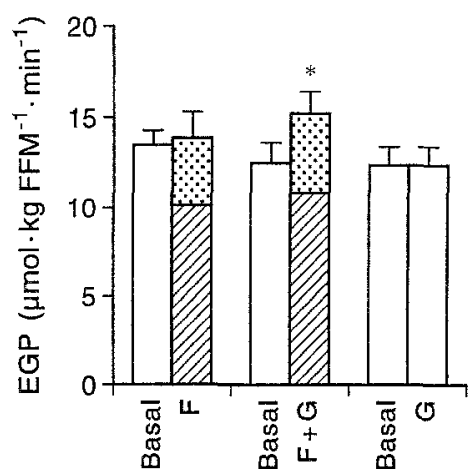

Table 4. Plasma glucose, insulin and glucagon concentrations in healthy subjects during baseline (time -30-0 min) and during administration of fructose, fructose + glucagon, or glucagon

\begin{tabular}{lllllll}
\hline & \multicolumn{2}{l}{ Glucose $(\mathrm{mmol} / \mathrm{l})$} & \multicolumn{3}{l}{ Glucagon $(\mathrm{ng} / \mathrm{l})$} \\
\cline { 2 - 7 } & $-30-0 \mathrm{~min}$ & $120-180 \mathrm{~min}$ & $-30-0 \mathrm{~min}$ & $120-180 \mathrm{~min}$ & $-30-0 \min$ & $120-180 \mathrm{~min}$ \\
\hline Fructose & $4.81 \pm 0.12$ & $5.16 \pm 0.14^{\mathrm{a}}$ & $29.9 \pm 4.1$ & $47.6 \pm 6.1^{\mathrm{b}}$ & $105 \pm 6$ & $103 \pm 4$ \\
Fructose + glucagon & $4.61 \pm 0.09$ & $5.96 \pm 0.23^{\mathrm{b}}$ & $34.4 \pm 4.8$ & $80.3 \pm 10.7^{\mathrm{b}}$ & $112 \pm 5$ & $233 \pm 9^{\mathrm{c}}$ \\
Glucagon & $4.81 \pm 0.09$ & $5.41 \pm 0.10^{\mathrm{a}}$ & $28.5 \pm 5.6$ & $35.3 \pm 3.6$ & $107 \pm 4$ & $210 \pm 26^{\mathrm{c}}$ \\
\hline
\end{tabular}

$n=8$ for all measurements, ${ }^{\mathrm{a}} p<0.05$ vs baseline; ${ }^{\mathrm{b}} p<0.01$ vs baseline; ${ }^{\mathrm{c}} p<0.001$ vs baseline

Fig. 3. Plasma ${ }^{13} \mathrm{C}$ glucose APE during administration of fructose $(\bigcirc)$ or fructose + glucagon $(\bullet)$ in lean healthy subjects

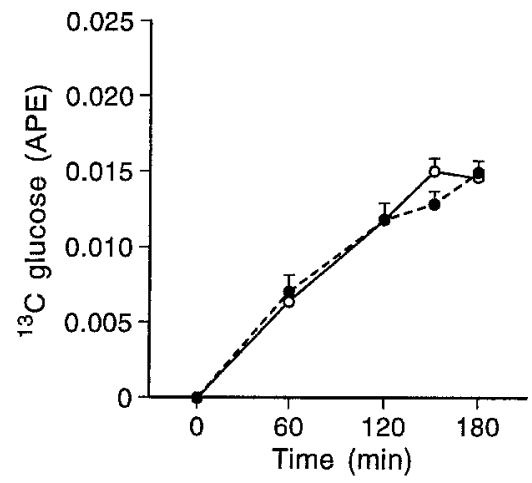




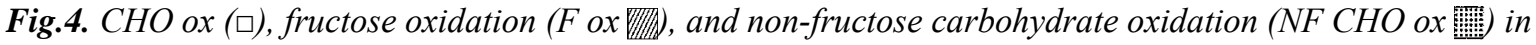
lean healthy subjects in the basal state and during fructose administration $(F)$, fructose administration and glucagon infusion $(F+G)$ and glucagon infusion alone $(G)$

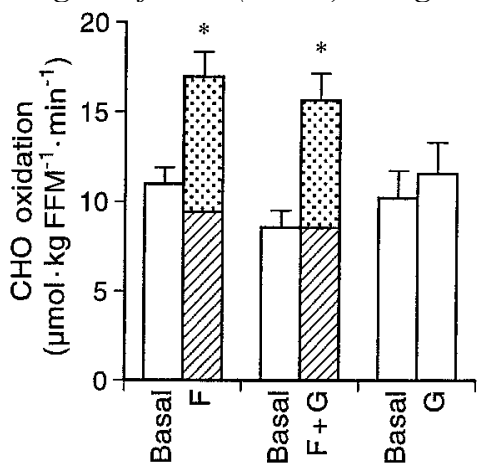

\section{Discussion}

Obese NIDDM subjects had an increased basal EGP [6, 9], the mechanisms of which remain unidentified. It has been suggested that an increased hepatic lipid oxidation may promote gluconeogenesis and secondarily enhance hepatic glucose production [25-28]. In the present study, our obese patients with normal glucose tolerance had increased concentrations of plasma non-esterified fatty acids and increased lipid oxidation rate. They also had higher than normal plasma insulin concentrations, suggesting insulin resistance. Their basal EGP was normal however, indicating that other factors are involved in the increased basal EGP of NIDDM patients.

Fructose ingestion failed to increase EGP in lean individuals, obese non-diabetic subjects, and obese patients with NIDDM. Gluconeogenesis was nonetheless a major pathway of ${ }^{13} \mathrm{C}$ fructose disposal, as indicated by a significant increase in plasma ${ }^{13} \mathrm{C}$ glucose APE. This process appeared to be stimulated to the same extent in both groups of subjects. The slight rise in plasma glucose and insulin concentrations induced by fructose may possibly have contributed to inhibit glycogenolysis and hepatic glucose output. However, it has been demonstrated that EGP does not increase in healthy humans infused with fructose even when plasma insulin and glucagon are maintained at constant levels by infusions of somatostatin, insulin and glucagon; since plasma glucose was also constant in these experiments, it indicated autoregulation of hepatic glucose production in healthy humans [5].

An increased glycogen synthesis has been shown to participate in the autoregulation of hepatic glucose production in healthy lean subjects [5] and is therefore likely to also function in obese NIDDM subjects. Nonoxidative fructose disposal, which corresponds to glycogen accretion from neoformed glucose [5] and de novo lipogenesis [29] were identical in lean subjects, obese non-diabetic subjects and obese patients with NIDDM. This suggests that stimulation of glycogen synthesis contributed to prevent an increase in EGP after fructose ingestion in all three groups. The failure of an increased glucose synthesis from fructose to enhance overall EGP in NIDDM mirrors the observation by other investigators that inhibition of gluconeogenesis in NIDDM patients did not decrease EGP and plasma glucose concentrations [30]. Together, these observations indicate that EGP also remains constant in obese non-diabetic subjects and in obese patients with NIDDM when gluconeogenesis is stimulated at the substrate level.

Incidentally, fructose concentrations were somewhat higher in obese compared to lean subjects. We have no obvious explanation for this difference. Although the fructose dose was normalized for FFM, differences in blood volume may possibly account for this variation. Alternatively, first pass hepatic extraction of fructose may be decreased in obese patients; however, their EGP was normal both in the basal state and during fructose administration. In all three groups of subjects, fructose concentration did not significantly change during the $3 \mathrm{rd}$ hour of administration, suggesting that hourly fructose absorption was roughly equal to hourly fructose ingestion by this time.

Glucagon plays a central role in the regulation of EGP. However, the autoregulation of EGP does not involve suppression of glucagon secretion because it is also present when glucagon concentrations are maintained constant by means of infusions of somatostatin and exogenous glucagon [2, 5]. Hyperglucagonaemia is nonetheless, frequently found in NIDDM patients, and many stimulate gluconeogenesis and EGP from an increased supply of endogenous gluconeogenic precursors. In order to further delineate the effects of hyperglucagonaemia on substrate-induced EGP, healthy subjects were further studied during ingestion of fructose with hyperglucagonaemia or during hyperglucagonaemia alone. In lean subjects, ingestion of ${ }^{13} \mathrm{C}$ fructose during moderate hyperglucagonaemia led to a $20 \%$ increase in EGP. The subsequent rise in blood 
glucose level was, however, modest, most likely due to a simultaneous increase in insulin secretion which stimulated peripheral glucose uptake, but may also have limited EGP. Glucagon alone failed to increase EGP, but induced a slight rise in plasma glucose and insulin. This stimulation of insulin secretion has been shown to be responsible for the inhibition of a glucagon-induced rise in hepatic glucose output [31]. It appears unlikely that glucagon increased EGP merely by increasing fructose conversion into glucose because fructose enters the gluconeogenic pathway at the level of the triose-phosphates, thus by-passing the major gluconeogenic steps controlled by glucagon. Non-oxidative fructose disposal, which corresponds to gluconeogenesis and de novo lipogenesis was not affected by glucagon. Glucagon may have increased the former while decreasing the latter, but such an effect is also unlikely because de novo lipogenesis is an energy-requiring process [32] and energy expenditure was not reduced by glucagon. EGP is the result of several processes including a) the glycogenolytic and gluconeogenic pathways which both contribute to the intrahepatic glucose-6-phosphate pool, b) glycogen synthesis and hydrolysis of glucose-6-phosphate, which together account for glucose-6-phosphate disposal. The absence of alterations in plasma ${ }^{13} \mathrm{C}$ glucose enrichment (which reflects the enrichment of intrahe-patic glucose6-phosphate) indicates that the relative rates of: a) ${ }^{13} \mathrm{C}$ glucose synthesis from fructose and b) production of unlabelled glucose from glycogen and other gluconeogenic precursors did not change during hyperglucagonaemia. This points to an activation of net glucose-6-phosphate hydrolysis during hyperglucagonaemia which may be due to a stimulation of glucose-6-phosphatase or an inhibition of hepatic glucokinase activities. Alternatively, the inhibition by glucagon of glycogen synthase may have led to an increase in glucose-6-phosphate concentration, which may have increased the flux through glucose-6phosphatase. The hypothesis that glucagon may play a key role in channelling glucose-6-phosphate towards its systemic release at the expense of glycogen synthesis finds support in the literature. In fasted dogs, acute suppression of glucagon secretion by an infusion of somatostatin and insulin to maintain basal insulin concentrations decreased EGP and the conversion of gluconeogenic precursors to plasma glucose, while simultaneously increasing hepatic glycogen content [33]. A similar observation was made in dogs infused for 3 days with stress hormones when glucagon infusion was abruptly stopped and the infusions of cortisol, epinephrine and growth hormone were continued [34]. Interestingly, neither fructose nor hyperglucagonaemia alone produced such effects. This indicates that fructose and glucagon produce two distinct alterations that act together to increase EGP. Fructose may have altered the intra-hepatic concentrations of one or several regulatory metabolites, while glucagon may have affected the activity of key enzymes on the pathways of glycogen synthesis and/or glucose-6-phosphate hydrolysis. It is furthermore tempting to speculate that these metabolic alterations were already present in obese NIDDM patients in the basal state, and were responsible for part or all of the enhanced EGP.

We conclude that during fructose administration: 1) gluconeogenesis is increased, but EGP remains constant in NIDDM, obese non-diabetic, and lean subjects; 2) in lean subjects, both an increased glucagonaemia and an enhanced supply of gluconeogenic precursors are required to increase EGP; this increase in EGP occurs without changes in the relative proportion of glucose 6-phosphate production from fructose and from other sources (i.e. glycogenolysis + gluconeogenesis from non-fructose precursors).

\section{Acknowledgements.}

This work was supported by grants from the Swiss National Science Foundation (32-37247.93), the Belgian Fonds de la Recherche Scientifique Médicale, the Foundation of Professor Dr. Max Cloëtta and the Foundation Raymond Berger.

\section{References}

1. Winkler B, Rathgeb I, Steele R, Altszuler N (1970) Conversion of glycerol to glucose in the normal dog. Am J Physiol 219: 497-502

2. Jenssen T, Nurjhan N, Consoli A, Gerich JE (1990) Failure of substrate-induced gluconeogenesis to increase overall glucose appearance in normal humans. J Clin Invest 86: 489-497

3. Jahoor F, Peters EJ, Wolfe RR (1990) The relationship between gluconeogenic substrate supply and glucose production in humans. Am J Physiol 258: E288-E296

4. Wolfe RR, Jahoor F, Shaw JHF (1987) Effect of alanine infusion on glucose and urea production in man. J Parenter Enter Nutr 11: 109111

5. Tounian P, Schneiter Ph, Henry S, Jéquier E, Tappy L (1994) Effects of infused fructose on endogenous glucose production, gluconeogenesis and glycogen metabolism in healthy humans. Am J Physiol 267: E710-E717

6. DeFronzo RA, Ferrannini E, Simonson DC (1989) Fasting hyperglycaemia in non-insulin dependent diabetes mellitus: contributions of excessive hepatic glucose production and impaired tissue glucose uptake. Metabolism 38: 387-395

7. Felig P, Wahren J, Hendler R (1978) Influence of maturity-onset diabetes on splanchnic glucose balance after oral glucose ingestion. Diabetes 27:121-126 
Published in: Diabetologia (1996), vol. 39, iss. 5, pp. 580-586.

Status: Postprint (Author's version)

8. Magnusson I, Rothman DL, Katz LD, Shulman RG, Shulman GI (1992) Increased rate of gluconeogenesis in type II diabetes mellitus. A

${ }^{13} \mathrm{C}$ nuclear magnetic resonance study. J Clin Invest 90:1323-1327

9. Tappy L, Acheson K, Curchod B et al. (1994) Overnight glucose metabolism in obese non-insulin-dependent diabetic patients and in healthy lean individuals. Clin Physiol 14: 251-265

10. Nurjhan N, Consoli A, Gerich J (1992) Increased lipolysis and its consequence on gluconeogenesis in non-insulin dependent diabetes mellitus. J Clin Invest 89: 169-175

11. Consoli A, Nurjhan N, Reilly JJJ et al. (1990) Mechanism of increased gluconeogenesis in non insulin-dependent diabetes mellitus. J Clin Invest 86: 2038-2045

12. Lefèbvre P, Paolisso G, Scheen A (1991) The role of glucagon in non-insulin-dependent (type 2) diabetes mellitus. In: Sakamoto N, Angel A, Hotta N (eds) New directions in research and clinical works for obesity and diabetes mellitus. Elsevier Science Publishers B. V., Amsterdam, pp 25-29

13. Tappy L, Acheson K, Normand S et al. (1992) Effects of infused amino acids on glucose oxidation, endogenous glucose production and ${ }^{13} \mathrm{C}$ glucose synthesis from ${ }^{13} \mathrm{C}$ bicarbonate in healthy human subjects. Am J Physiol 262: E826-E833

14. Boden G, Tappy L, Jadali F, Hoeldtke RD, Rezvani I, Owen OE (1990) Role of glucagon in disposal of an amino acid load. Am J Physiol 259: E225-E232

15. Durnin JVGA, Womersley J (1974) Body fast assessment for total body density and its estimation from skinfold thickness: measurements on 481 men and women aged from 16 to 72 years. Br J Nutr 32: 77-97

16. Jéquier E, Felber J (1987) Indirect calorimetry. Baillieres Clin Endocrinol Metab 1: 911-935

17. DeBodo R, Steele R, Altzuler N, Dunn A, Bishop J (1963) On the hormonal regulation of carbohydrate metabolism: studies with ${ }^{14}$ Cglucose. Recent Prog Horm Res 19: 445-488

18. Chiasson JL, Liljenquist JE, Lacy WW, Jennings AS, Cherrington AD (1977) Gluconeogenesis: methodological approach in vivo. Fed Proc 36: 229-235

19. Tappy L, Owen O, Boden G (1988) Effect of hyperinsulinemia on urea pool size and substrate oxidation rates. Diabetes 37: $1212-1217$

20. Livesey G, Elia M (1988) Estimation of energy expenditure, net carbohydrate utilization, and net fat oxidation and synthesis by indirect calorimetry evaluation of errors with special reference to the detailed composition of foods. Am J Clin Nutr 47: 608-628

21. Robert JJ, Koziet J, Chauvet D, Darmaun D, Desjeux JF, Young VR (1987) Use of ${ }^{13}$ C-labeled glucose for estimating glucose oxidation: some design considerations. J Appl Physiol 63:1725-1732

22. Gay LJ, Schneiter P, Schutz Y, Di Vetta V, Jéquier E, Tappy L (1994) A non-invasive assessment of hepatic glycogen kinetics and postabsorptive gluconeogenesis in man. Diabetologia 37: 517-523

23. Schmidt FH (1961) Die enzymatische Bestimmung von Glucose und Fructose nebeneinander. Klin Wochenschr 39:1244-1247

24. Hawk P (1947) Practical physiological chemistry. 12th edn. Blakiston, Toronto, pp 814-822

25. Menahan A, Wieland O (1969) The role of endogenous lipid in gluconeogenesis and ketogenesis in perfused rat liver. Eur J Biochem 9:182-188

26. Williamson JR, Kreisberg RA, Felts PW (1966) Mechanism for the stimulation of gluconeogenesis by fatty acids in perfused rat liver. Biochemistry 56: 247-254

27. Fanelli C, Calderone S, Epifano L et al. (1993) Demonstration of critical role for free fatty acids in mediating counter-regulatory stimulation of gluconeogenesis and suppression of glucose utilization in humans. J Clin Invest 29: 1617-1622

28. Clore JN, Glickman PS, Nestler JE, Blackard WG (1991) In vivo evidence for hepatic autoregulation during FFA-stimulated gluconeogenesis in normal humans. Am J Physiol 261: E425-E429

29. Schwarz JM, Neese R, Shackleton C, Hellerstein MK (1993) De novo lipogenesis during fasting and oral fructose in lean and obese hyperinsulinemic subjects. Diabetes 42 [Suppl] 1:39 A (Abstract)

30. Puhakainen I, Koivisto VA, Yki-Jarvinen H (1991) No reduction in total hepatic glucose output by inhibiton of gluconeogenesis with ethanol in NIDDM patients. Diabetes 40:1319-1327

31. Ferrannini E, DeFronzo RA, Sherwin RS (1982) Transient hepatic response to glucagon in man: role of insulin and hyperglycaemia. Am J Physiol 242: E73-E81

32. Flatt JP (1978) The biochemistry of energy expenditure. In: Bray GA (ed) Recent advances in obesity research. Newman Publishing, London, pp 211-228

33. McGuinness OP, Murrell S, Moran C, Bracy D, Cherrington AD (1994) The effect of acute glucagon removal on the metabolic response to stress hormone infusion in the conscious dog. Metabolism 43:1310-1317

34. Hendrick GK, Wasserman DH, Frizzell RT et al. (1992) The importance of basal glucagon in maintaining hepatic glucose production during a prolonged fast in the conscious dog. Am J Physiol 263: E541-E549 